\title{
The Prevention of Lower Urinary Tract Symptoms (PLUS) in girls and women: Developing a conceptual framework for a prevention research agenda
}

\author{
Sonya S. Brady PhD $^{1}$ (D) ～Tamara G. Bavendam MD, MS $^{2}$ | \\ Amanda Berry MSN, CRNP, PhD ${ }^{3}$ | Cynthia S. Fok MD, MPH \\ Sheila Gahagan MD $^{5}$ | Patricia S. Goode MSN, MD ${ }^{6,7}$ \\ Cecilia T. Hardacker MSN, RN, CNL ${ }^{8,9}$ | Jeni Hebert-Beirne PhD, MPH ${ }^{10}$ | \\ Cora E. Lewis MD, MSPH ${ }^{11}$ ｜ Jessica B. Lewis MFT, MPhil ${ }^{12}$ | \\ Lisa Kane Low PhD, CNM ${ }^{13}$ ｜ Jerry L. Lowder MD, MSc ${ }^{14}$ | \\ Mary H. Palmer PhD ${ }^{15} \quad$ Jean F. Wyman PhD ${ }^{16} \quad$ Emily S. Lukacz MD ${ }^{17}$ \\ For the Prevention of Lower Urinary Tract Symptoms (PLUS) Research Consortium

\footnotetext{
${ }^{1}$ Division of Epidemiology \& Community Health, University of Minnesota School of Public Health, Minneapolis, Minnesota

${ }^{2}$ National Institute of Diabetes and Digestive and Kidney Diseases, National Institutes of Health, Bethesda, Maryland

${ }^{3}$ Division of Urology, Children's Hospital of Philadelphia, Philadelphia, Pennsylvania

${ }^{4}$ Department of Urology, University of Minnesota Medical School, Minneapolis, Minnesota

${ }^{5}$ Division of Academic General Pediatrics, University of California San Diego, San Diego, California

${ }^{6}$ Division of Gerontology, Geriatrics, and Palliative Care, University of Alabama at Birmingham, Birmingham, Alabama

${ }^{7}$ Birmingham/Atlanta Veterans Affairs Geriatric Research, Education, and Clinical Center, Birmingham, Alabama

${ }^{8}$ Howard Brown Health, Chicago, Illinois

${ }^{9}$ Rush University College of Nursing, Chicago, Illinois

${ }^{10}$ Division of Community Health Sciences, University of Illinois at Chicago, School of Public Health, Chicago, Illinois

11 Department of Epidemiology, School of Public Health, University of Alabama at Birmingham, Birmingham, Alabama

12 Yale School of Public Health, New Haven, Connecticut

${ }^{13}$ School of Nursing, Women's Studies, Department of Obstetrics and Gynecology, University of Michigan, Ann Arbor, Michigan

${ }^{14}$ Division of Female Pelvic Medicine and Reconstructive Surgery, Washington University in St. Louis School of Medicine, St. Louis, Missouri

${ }^{15}$ School of Nursing, University of North Carolina at Chapel Hill, Chapel Hill, North Carolina

${ }^{16}$ School of Nursing, University of Minnesota, Minneapolis, Minnesota

${ }^{17}$ Division of Female Pelvic Medicine \& Reconstructive Surgery, University of California San Diego, San Diego, California
}

Correspondence

Sonya S. Brady, PhD, Division of Epidemiology and Community Health, University of Minnesota School of Public Health, 1300 South Second Street, Suite 300, Minneapolis, MN 55454.

Email: ssbrady@umn.edu
Aims: The Prevention of Lower Urinary Tract Symptoms (PLUS) Research Consortium was established by the National Institutes of Health in 2015 to expand research beyond the detection and treatment of lower urinary tract symptoms (LUTS) to the promotion and preservation of bladder health and prevention of LUTS in girls and women. While many multi-disciplinary scientific networks focus on pelvic floor

Roger Dmochowski led the peer-review process as the Associate Editor responsible for the paper. 


\section{Funding information}

National Institutes of Health (NIH), Grant numbers: U01DK106786, U01DK106853, U01DK106858, U01DK106898, U01DK106893, U01DK106827, U01DK106908, U01DK106892; National Institute on Aging; NIH Office of Research on Women's Health; NIH Office of Behavioral and Social Sciences Research

dysfunction and LUTS, the PLUS Consortium stands alone in its focus on prevention. This article describes the PLUS approach to developing a conceptual framework to guide the Consortium's initial prevention research agenda.

Methods: The conceptual framework was informed by traditional social ecological models of public health, biopsychosocial models of health, Glass and McAtee's Society-Behavior-Biology Nexus, and the World Health Organization's conceptual framework for action on the social determinants of health.

Results: The PLUS conceptual framework provides a foundation for developing prevention interventions that have the greatest likelihood of promoting and preserving bladder health among diverse populations.

Conclusions: PLUS Consortium work is premised on the notion that programs, practices, and policies designed to promote health will have optimal impact if the conceptual foundation upon which efforts are based is comprehensive and informed by multiple disciplines. The PLUS conceptual framework is broadly applicable to domains of health that have historically focused on the treatment of illness and symptoms rather than the promotion of health. It is also applicable to domains of health that have been examined from a predominantly biological or social ecological perspective, without integration of both perspectives.

\section{K E Y W O R D S}

bladder health, conceptual framework, girls, lower urinary tract symptoms, prevention, social ecology, women

\section{1 | INTRODUCTION}

The promotion of health and prevention of disease are essential components of public health. ${ }^{1}$ In many domains of health, however, research and practice are focused primarily on the identification and treatment of disease rather than the promotion of public health. The lower urinary tract is one such domain. Lower urinary tract symptoms (LUTS) encompass a variety of bothersome storage and emptying symptoms, including urgency urinary incontinence (ie, strong urge "to go" and losing urine before reaching a toilet), stress urinary incontinence (eg, losing urine with physical activity or increases in abdominal pressure such as a cough or sneeze), frequent and/or urgent urination, nocturnal enuresis (ie, bedwetting), difficulty urinating, dribbling after urination, and bladder or urethral pain before, during, or after urination. ${ }^{2,3}$ LUTS are extremely common, with more than 200 million people worldwide and over $15 \%$ of women aged 40 years or older suffering from urinary incontinence. ${ }^{4,5}$ Overactive bladder (OAB), a subset of LUTS, is characterized by urinary urgency, with or without urgency incontinence, and usually with frequent daytime and nighttime urination. ${ }^{3}$ In the United States (U.S.) and Europe, prevalence of OAB in adults has been estimated at approximately $16 \% .^{6,7}$ Substantial public and private investments have been made to diagnose and treat conditions associated with LUTS. For example, there are currently over 20 medications for management of $\mathrm{OAB}$; historically, there have been over 200 different surgical procedures for stress urinary incontinence. ${ }^{8,9}$ The total U.S. economic burden, including lost work productivity, of $\mathrm{OAB}$ with urgency urinary incontinence was estimated to be $\$ 65.9$ billion in 2007, with a projected annual estimate of $\$ 82.6$ billion by $2020 .^{10}$

Prevention of LUTS is particularly important for girls and women. Women are 2-3 times more likely to experience urinary incontinence and four times more likely to experience a urinary tract infection in comparison to men. ${ }^{11-14}$ In a large, population-based sample of individuals from the United States, United Kingdom, and Sweden, $71 \%$ of men and $75 \%$ of women reported at least one LUTS. ${ }^{15}$ Women are at higher risk for specific LUTS than men due to the anatomy and physiology of the female urogenital system. ${ }^{16}$ Women's hormonal milieu, experiences during pregnancy and childbirth, and gendered societal experiences are additional contributors. ${ }^{16,17}$ For example, women may encounter greater barriers to toileting in public spaces (accessibility, privacy, safety, and cleanliness). ${ }^{17}$ While men report more problems than women with bladder emptying, women report more problems with storage and overall LUTS. ${ }^{18}$ Moreover, LUTS tend to begin earlier in the life course for women than for men.,16 
The prevalence and incidence of LUTS among women varies across the life course. Estimates of urinary incontinence in women range from $10 \%$ to $50 \%$, depending on the definition of incontinence and age of the population being studied. ${ }^{16,19}$ Generally, LUTS in girls include urinary tract infections and nocturnal enuresis. ${ }^{20,21}$ In contrast, LUTS in women predominantly include stress urinary incontinence during the reproductive years; urgency and mixed urinary incontinence with increasing age ${ }^{4}$; and urinary tract infections after menopause. ${ }^{22}$ Early prevention of LUTS is important to public health promotion, as the early experience of LUTS may predispose girls and women to reoccurrence, worsening, or new onset of LUTS with age. ${ }^{22,23}$ Prevention of LUTS is important to the promotion of both physical health and emotional well-being. Anxiety or depression is reported by more than $50 \%$ of women with LUTS, and social isolation is common. ${ }^{24,25}$ Thus, LUTS have substantial impact on the health and quality of life of girls and women across the life course and are important to prevent at all ages.

\section{1 | Challenging the status quo}

Traditionally, LUTS have been viewed by western health care providers from a medical model perspective that promotes a reactive response. In this model, girls or women develop symptoms, seek help, and receive treatment that may or may not lead to cure or amelioration of symptoms. Despite the medical model perspective, LUTS have been largely underdiagnosed and undertreated, with up to $75 \%$ of women with urinary incontinence not seeking care. ${ }^{26}$ This may be attributed to a sense of embarrassment or stigma that hinders health care seeking and open communication, or to lack of knowledge on the part of affected women or providers, including the misperception that LUTS are a normal part of being female or aging. ${ }^{27-29}$ Over the past several decades, there has been a proliferation of advertising campaigns for products designed to help women manage LUTS through pharmaceuticals and incontinence aids. ${ }^{30,31}$ While advertisements for LUTS products may help to reduce stigma, ${ }^{32}$ they may also serve to normalize the experience of LUTS. Women may approach their providers for medication to treat LUTS, or they may be misled to think their symptoms can only be managed by incontinence containment products. Thus, both the medical model and profit-incentivized industries ${ }^{33}$ have contributed to societal norms focused on the treatment and self-management of LUTS rather than prevention.

Additionally, financial incentives for health care systems and providers have been linked to the identification and treatment of disease, rather than the promotion of health and prevention of disease. ${ }^{34}$ While investment in the prevention of other prevalent conditions such as obesity, ${ }^{35}$ cardiovascular disease, ${ }^{36}$ colorectal cancer, ${ }^{37}$ and infectious diseases ${ }^{38}$ has increased, investment in the prevention of LUTS has lagged.
A small body of literature has identified potentially modifiable risk factors for LUTS and examined the impact of prevention strategies ${ }^{39-42}$; this literature has begun to expand the focus of research and practice toward the prevention of LUTS among girls and women. However, to shift the prevailing health care paradigm to an emphasis on prevention, coordinated efforts on the part of scientists and health care professionals are needed.

\section{2 | MATERIALS AND METHODS}

The Prevention of Lower Urinary Tract Symptoms (PLUS) Research Consortium was established in 2015 to expand research beyond the detection and treatment of LUTS to the promotion and preservation of bladder health and prevention of LUTS in girls and women. ${ }^{43}$ While many multidisciplinary research networks focus on pelvic floor dysfunction and LUTS, the PLUS Consortium stands alone in its focus on prevention. The PLUS Consortium is comprised of a transdisciplinary network of professionals, including community advocates, health care professionals, and scientists specializing in pediatrics, adolescent medicine, gerontology and geriatrics, nursing, midwifery, behavioral medicine, preventive medicine, psychiatry, neuroendocrinology, reproductive medicine, female pelvic medicine and reconstructive surgery, urology, infectious diseases, clinical and social epidemiology, prevention science, medical sociology, psychology, women's studies, sexual and gender minority health, community-engaged research, community health promotion, scale development, research methods, and biostatistics. Early conversations between network members acknowledged the diversity of girls and women with respect to sexual orientation and gender identity (SOGI). Members agreed to include SOGI measures in PLUS studies and to develop inclusion/ exclusion criteria for cisgender and transgender individuals that fit the scientific objectives of each study.

To shift research, practice, and policies to a focus on health, the PLUS Consortium identified two initial tasks that it pursued in parallel. First, the Consortium drafted a research definition of bladder health. ${ }^{44}$ Consistent with the World Health Organization's definition of health, ${ }^{45}$ the PLUS Consortium conceptualizes bladder health as "a complete state of physical, mental, and social well-being related to bladder function, and not merely the absence of LUTS," with function that "permits daily activities, adapts to short term physical or environmental stressors, and allows optimal wellbeing (eg, travel, exercise, social, occupational, or other activities)." Second, the Consortium adopted a prevention science paradigm and developed a conceptual framework to guide the Consortium's initial prevention research agenda. The Consortium began this task by establishing a shared understanding of prevention science among its diverse members. The Consortium then drew from separate, but 
complementary theoretical traditions and contemporary writings to develop the PLUS conceptual framework. The purpose of this manuscript is to describe the PLUS approach in developing a conceptual framework to guide the Consortium's initial prevention research agenda.

\section{3 | RESULTS}

\subsection{Idoption of a prevention science paradigm}

An underlying premise of prevention science is that one must understand what leads to disease and how disease can be prevented in order to promote and preserve health. Prevention science involves the systematic study of potential precursors to human dysfunction and health, termed risk and protective factors, respectively. ${ }^{46,47}$ Risk factors are those attributes, characteristics, or exposures of an individual that increase the likelihood of developing a disease. In contrast, protective factors enhance health and lessen the likelihood that dysfunction will occur in response to risk factors. Risk and protective factors at different levels of social ecology have also been referred to as social determinants of health. ${ }^{48,49}$ Prevention scientists conduct etiologic studies to identify risk and protective factors across different levels of biology and the social ecology that surrounds individuals. ${ }^{46,47}$ They also develop and test prevention interventions aimed at modifying risk and protective factors, with the goal of promoting health and preventing or moderating major dysfunction before onset of disease or disorder. Prevention science applies a life course developmental perspective to etiologic research and rigorous intervention methodology. ${ }^{50}$ Dissemination of findings are expected to impact health promotion programs, practices, and policies, and in turn, the health of populations across the life course.

\section{2 | Development of the PLUS conceptual framework}

Developing a conceptual framework that encompasses all facets of social ecology, integrates biology with social ecology, and emphasizes a life course perspective is key to the adoption of a prevention science paradigm. The PLUS conceptual framework is informed by traditional social ecological models of public health and biopsychosocial models of health. It also integrates contemporary conceptualizations of public health that explicitly acknowledge the role of societal structures in creating health inequities-namely, Glass and McAtee's ${ }^{51}$ Society-Behavior-Biology Nexus and the World Health Organization's Conceptual Framework for Action on Social Determinants of Health. ${ }^{52}$ In the sections below, each model and framework that informed the PLUS conceptual framework is reviewed. These resources may serve as valuable tools in effecting other paradigm shifts in health among scientists, practitioners, and policymakers.

Social ecological conceptualizations of public health situate individuals within environments of interrelated, interacting, and nested spheres of influence on health and health behavior. Social ecological models traditionally draw from theories of individual behavior and interpersonal relations, which may be thought of as proximal social influences, as well as sociological structures such as institutions, communities, cultures, and policy landscapes, which may be thought of as distal social influences. ${ }^{53}$ Social ecological models hail from the work of behavioral scientists and systems theorists, including Brofenbrenner's pioneering conceptualization of systems at multiple levels of social ecology that influence child development. ${ }^{54} \mathrm{~A}$ social ecological conceptualization allows public health scientists and practitioners to consider individuals within an ecosystem of risk and protective factors beginning with the intrapersonal level (genetics, psychology, health status) and extending outward to the interpersonal (family, peer, partner influence), institutional (school, work, health care system), community (cultural norms), and societal (policies, laws, economics) levels. By identifying prevention opportunities at multiple levels of influence, public health professionals aim to effectively promote both individual and population health.

Social ecological models have increasingly been applied in health promotion and intervention contexts over the past 40 years. ${ }^{55}$ A variety of factors have led to this trend, including increased attention to social determinants of health and health inequities; recognition of the limitations of focusing only on linear causality via proximal individual-level risk factors; and frustration with individual behavior change interventions that do not account for contextual influences. ${ }^{55-58}$ Social ecological approaches have been applied most often in public health interventions to change behaviors such as nutrition intake, physical activity, and smoking. ${ }^{59}$ For example, a behaviorally focused ecologic approach to improve nutrition and physical activity within a population might include education for individuals; modifying home cooking practices for families; engaging schools and workplaces to support access to fresh, healthy food options; fostering healthy norms and ensuring access to healthy foods in the community; and taxing unhealthy foods and funding the creation of public exercise spaces. Social ecological approaches have been utilized less often to understand physiologic dysfunction, such as LUTS. Public health scientists and organizations increasingly value multilevel approaches to public health promotion that address a broad array of influences, from genes to macroeconomics. ${ }^{60-62}$

As behavioral scientists began to widen the lens of social ecology to explain health and disease, physicians and other health care professionals began to integrate biology and social context. Roughly 40 years ago, biopsychosocial (BPS) models of health were proposed as an alternative to the prevailing 
biomedical model. ${ }^{63}$ Engel advocated a new multilevel systems approach that would acknowledge not only the organic or biological basis of disease, but also "the patient, the social context in which he lives, and the complementary system devised by society to deal with the disruptive effects of illness." Essentially holistic, the basic assumption of the BPS model is that all illness is a complex reciprocal interaction of biological, psychological, and social factors. ${ }^{64}$ The BPS model, similar to other social ecological models, has been proposed as a framework for understanding conditions that are determined by interrelated, interacting risk and protective factors, such as multimorbidity ${ }^{65}$ and the obesity epidemic. ${ }^{66}$ Application of the BPS model is not without criticism, however. For example, Henningsen ${ }^{67}$ observed that attention to the "bio" component in the BPS model has grown at the expense of "psychological" and "social" components, potentially because biologically based treatments are preferred by many medical practitioners and confer greater economic advantage to institutions. Further, Henningsen noted that a focus on "psychosocial" determinants of health proximal to the individual has resulted in missed opportunities to focus on important "sociocultural" determinants of health that are distal to the individual. ${ }^{67}$

\subsection{1 | Glass and McAtee's Society-Behavior- Biology Nexus}

Over a decade ago, Thomas Glass and Matthew McAtee ${ }^{51}$ developed the Society-Behavior-Biology Nexus to integrate social ecological and biological influences on health. Their model depicts nested spheres of influences both within and outside of the individual, who moves through time from infancy to old age. The Society-Behavior-Biology Nexus situates the individual within nested systems of social organization, ranging outward to encompass the micro-level (family, social networks), mezzo-level (schools, worksites, communities, health care systems), macro-level (states, nations), and global level (geopolitics, economic and environmental dynamics). Unlike most social ecological models, the Society-Behavior-Biology Nexus explicitly highlights nested systems of biological organization within the individual, ranging inward to encompass multi-organ systems, cellular level influences, sub-cellular/molecular level influences, and the genomic substrate.

The Society-Behavior-Biology Nexus integrates social ecology and biology through the concepts of embodiment ${ }^{68}$ and gene-by-environment interactions. Social ecological risk and protective factors, which Glass and McAtee ${ }^{51}$ framed as societal constraints and opportunities, can become embodied with respect to biological function. Expression of biologically based predispositions toward health or disease can also be triggered by specific social ecological contexts. Glass and McAte $^{51}$ developed the concept of a risk regulator to emphasize societally imposed constraints against and opportunities for health. Risk regulators include material conditions; discriminatory practices, policies, and attitudes; neighborhood and community conditions; behavioral norms, rules, and expectations; conditions of work; and laws, policies, and regulations. Risk regulators can influence health and disease through multiple, potentially complex pathways over time. For example, different risk and protective factors might accumulate, influence one another, and influence health outcomes in a bi-directional fashion. Identifying the initial cause of a health effect is less important than knowing that a cluster of risk and protective factors appears to play a causal role in the maintenance of health, or the generation or exacerbation of poor health. For this reason, prevention programs must address societally imposed constraints on health early in life and throughout the life course in order to be effective.

The PLUS Consortium chose to adapt Glass and McAtee's ${ }^{51}$ model because it stimulates thought about a broad spectrum of factors that may influence health across the life course. Figure 1 depicts a condensed version of the PLUS conceptual framework to guide studies investigating the etiology and prevention of LUTS and promotion of bladder health. This framework shows how environmental risk and protective factors (eg, constrained or unconstrained toilet access) can become embodied in the structure and functioning of biological systems that affect bladder health and the development of LUTS. The framework also includes the potential for gene-by-environment interactions. Genetic and biological predispositions toward bladder health and the development of LUTS may be more likely to be expressed in specific social and environmental contexts. Throughout the life course, individual behavior is a critical determinant of bladder health and LUTS. Whereas Glass and McAtee ${ }^{51}$ depicted behavior within an arrow representing the life course, the PLUS Consortium depicts bladder health and LUTS within this arrow (see center of Figure 1). Behavior is grouped with cognitive, affective, and psychosocial attributes of the individual. Prevention strategies can target specific social ecological determinants of bladder health and LUTS, as well as behaviors that can ameliorate genetic and biological vulnerabilities.

\subsection{2 | World Health Organization's (WHO) Conceptual Framework for Action on Social Determinants of Health}

Glass and McAtee's ${ }^{51}$ Society-Behavior-Biology Nexus draws attention to the role of risk regulators in creating health inequities. However, the framework is not explicit about how risk regulators are created and maintained. The World Health Organization (WHO) established a Commission on Social Determinants of Health to summarize evidence 


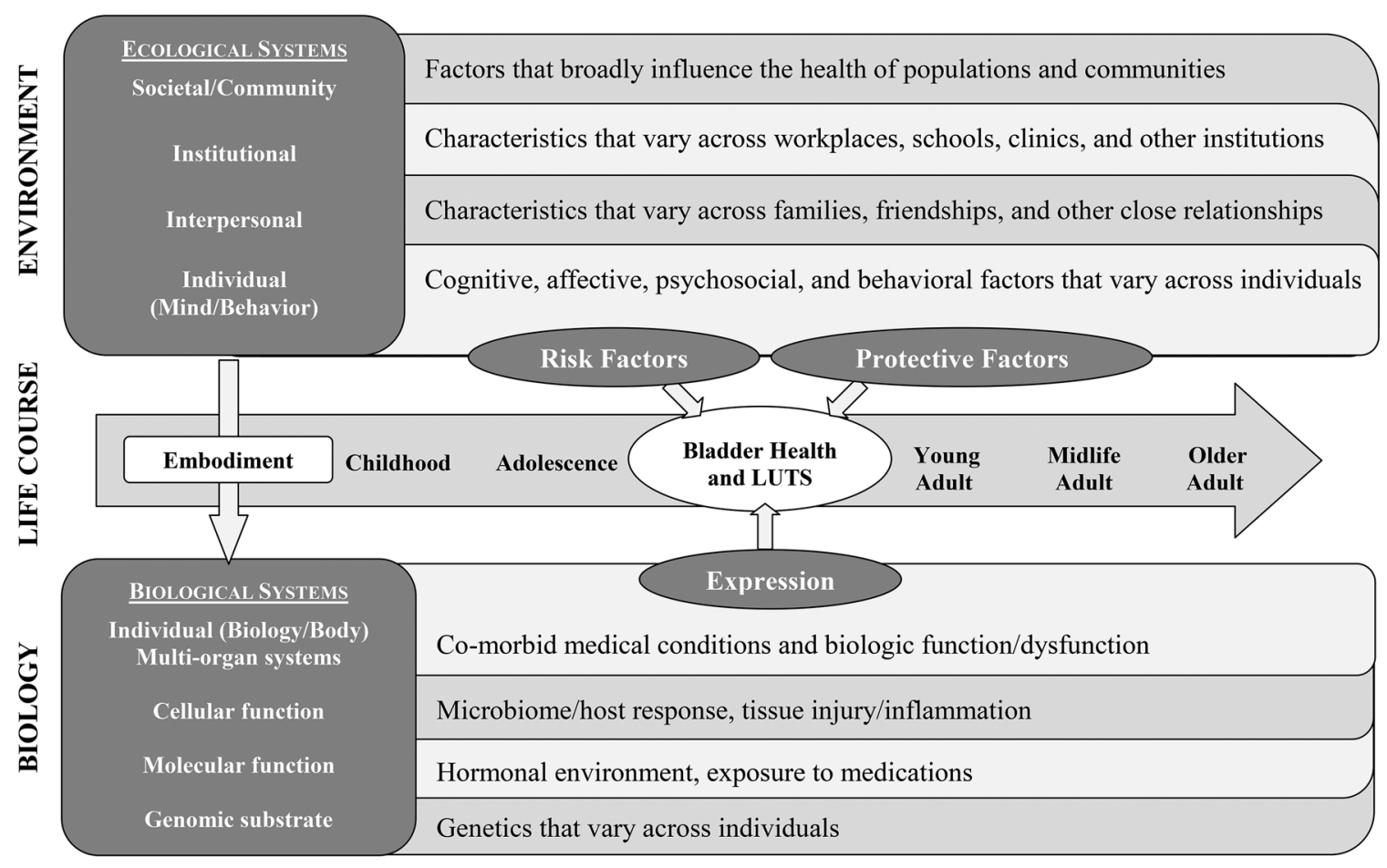

FIGURE 1 Prevention of Lower Urinary tract Symptoms (PLUS) among girls and women: A conceptual framework adapted from Glass and McAtee ${ }^{51}$

for how the structure of societies-through governance, policies, culture, and values-determines the health of populations. ${ }^{52}$ Namely, a society stratifies its population according to income, education, occupation, gender, race, ethnicity, and other factors. From these social stratifications, social hierarchies result. Position within the social hierarchy in turn shapes specific social determinants of health. Thus, the WHO framework separates structural determinants of health inequities, the distal factors rooted in a society's political, economic, and social structures (eg, macroenonomic and public policies), from social determinants of health, a more commonly understood term that refers to proximal factors rooted in one's social position (eg, living and working conditions). The WHO framework asserts that a society produces health and disease among its citizens. The framework also asserts that policymakers bear responsibility for creating and maintaining health equity among populations, as well as redressing the structural factors that produce under-resourced communities and health inequities.

Inclusion of the WHO perspective within the PLUS conceptual framework has allowed the Consortium to intentionally consider issues of health equity and social justice in its development of a population-based prevention science agenda. Health disparities ${ }^{69}$ are defined as differences in health that are closely linked with economic, social, or environmental disadvantage. Whereas a health disparity highlights no explicit cause for the disparity, a health inequity highlights a difference in health that is imposed by society and is unnecessary, avoidable, and unjust. $^{70,71}$ The WHO framework highlights the importance of policy-based interventions as part of a multi-level population-based prevention strategy. Insufficient attention to policies that impact the conditions in which people live and their opportunities to be healthy could inadvertently generate or widen health inequities over time and across generations. This can occur even when the health of all communities is improving. The WHO framework can enhance the impact of the PLUS Consortium by encouraging prevention interventions at distal, structural levels (eg, federal policies) rather than solely focusing on individual and proximal levels of influence in the environment (eg, the built environment). While prevention interventions that aim to influence social determinants of health typically function at the community level, prevention interventions at the structural level aim to change a society's political, economic, and social systemsthe factors that give rise to disadvantageous social groupings and socioeconomic positions.

\section{3 | Applying the PLUS conceptual framework to build a prevention research agenda}

Initial PLUS Consortium activities were designed to engage members in a series of analytic processes to develop the PLUS conceptual framework and inform the Consortium's initial prevention research agenda. First, Consortium 


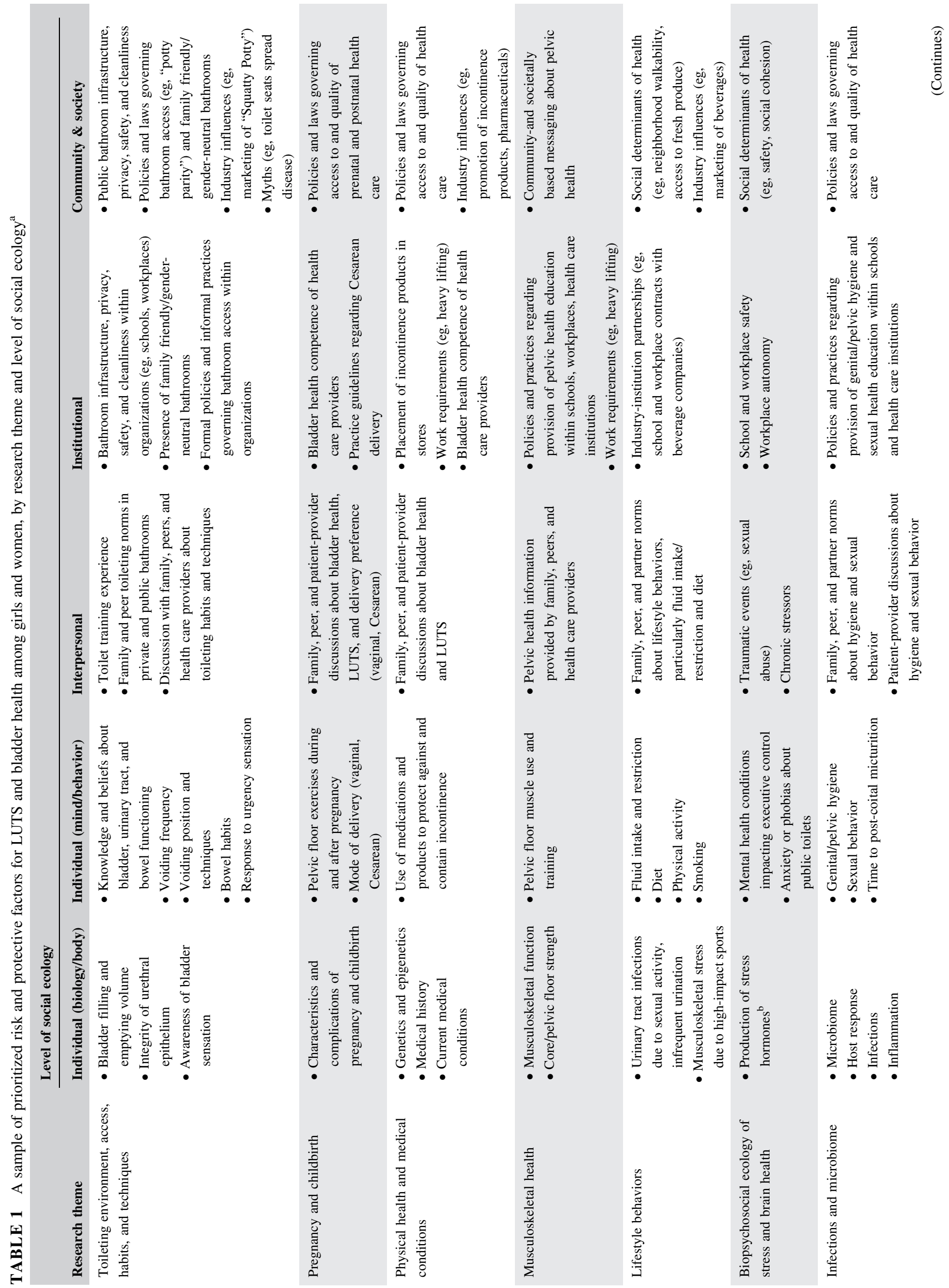


members identified levels of social ecology and biology that are relevant to the PLUS Consortium. As shown in Table 1 (see columns), Consortium members divided individuallevel risk and protective factors into those that were biological (biology/body) and those that were cognitive, affective, or behavioral (mind/behavior). The Consortium separately considered interpersonal risk and protective factors for LUTS and bladder health. Because of the Consortium's life course perspective, interpersonal factors include the influence of parents and other family members during early life (eg, toileting techniques and habits), as well as peers and partners later in life. Consistent with social ecological models of public health and Glass and McAtee's ${ }^{51}$ notion of risk regulators, the Consortium focused on institutional factors that may influence LUTS and bladder health (eg, access to bathroom facilities within schools and workplaces; cleanliness, privacy, and safety of facilities). Consistent with the WHO distinction between social determinants of health and structural determinants of health inequities, ${ }^{52}$ the Consortium focused on community and societal level factors that may influence LUTS and bladder health (eg, neighborhood safety and cohesion; public bathroom infrastructure and access; policies and laws governing control over fluid intake and voiding opportunity in schools and workplaces).

Once the Consortium had identified different levels of biology and social ecology that may influence LUTS and bladder health, members focused on generating potential risk and protective factors within each level of the framework. Potential factors were generated based on existing literature, theories of health and human behavior, and clinical and professional observation. The nested levels of influence within and outside of the individual served as prompts to consider risk and protective factors that may have been outside of one's area of expertise. A conceptual framework encapsulates what is possible to study; thus, it is intentionally comprehensive. The Consortium generated over 600 potential risk and protective factors. While such an exercise and resulting product appeared overwhelming, this activity was critical to building a prevention science research agenda. A systematic approach to studying potential precursors to LUTS and bladder health ideally begins with a comprehensive list of all that is possible to study.

PLUS Consortium members next engaged in an activity to prioritize risk and protective factors for study. By design, the interests of individual research members and teams within the Consortium are broad. It is thus not surprising that from the original list of over 600 potential risk and protective factors, over 400 factors remained after initial prioritization (see supplemental appendix). Prioritized risk and protective factors were clustered into eight broad research themes to facilitate the selection of factors 
for study. Table 1 organizes several of the PLUS Consortium's prioritized factors by research theme (see rows) and level of ecology (see columns).

The organization of risk and protective factors by research theme and level of ecology can serve as a tool to generate study-specific conceptual models. Whereas a conceptual framework encapsulates what is possible to study, a conceptual model encapsulates what a research team has prioritized and chosen to study. ${ }^{72}$ A conceptual model shows the mechanisms by which specific risk and protective factors may be linked with health outcomes. Figure 2 depicts one example of a conceptual model that emerged through discussion. In this example, girls who attend schools and women who work in occupational settings where policies, norms, and practices prohibit timely access to bathrooms (ie, autonomy) may restrict their fluid intake and hold urine until it is painful or urine leakage occurs. Institutional policies, norms, and practices may also impact perceived privacy, safety, and cleanliness of bathrooms, which in turn may lead to fluid restriction and delayed voiding. In addition, perceived cleanliness of bathrooms may lead to adjustment of toileting position (eg, hovering versus sitting). Behavioral habits (eg, fluid restriction, delayed voiding, hovering) may in turn increase the likelihood of adverse health outcomes (see Figure 2).

In addition to identifying and organizing potential determinants of LUTS and bladder health according to different levels of the ecological and biological systems depicted in Figure 1, Consortium members delineated different life stages that are relevant to PLUS (see Table 2). ${ }^{73-75}$ The PLUS Consortium acknowledges variation within a chronological age period and views developmental status and events related to the lower urinary tract as more relevant to bladder health than chronological age. Developmental stages are delineated by chronological age to provide a rough index of who may be impacted by specific aspects of social ecology. Table 2 shows how the social ecological context of a female individual may vary by life stage. A comprehensive list of all contextual factors that vary by development is not shown. Rather, Table 2 summarizes factors judged by the PLUS Consortium to be particularly relevant to LUTS and bladder health. Table 2 illustrates the importance of studying girls and women across the life course.

\section{4 | DISCUSSION}

As the PLUS Consortium evolves, its conceptual framework and supporting materials will be modified as new terminology, concepts, and risk and protective factors for LUTS and bladder health are identified. Thus, the Consortium intends to be open and agile in its ability to respond to new developments in science and society.

The Consortium has begun to develop a prevention research agenda that is applying the PLUS conceptual framework presented in this manuscript. The framework is not only of value in selecting risk and protective factors that may influence LUTS and bladder health, but also in selecting potential confounders-those variables that may influence both the hypothesized predictor and outcome variable, resulting in a spurious (false) association. ${ }^{76}$ By identifying,

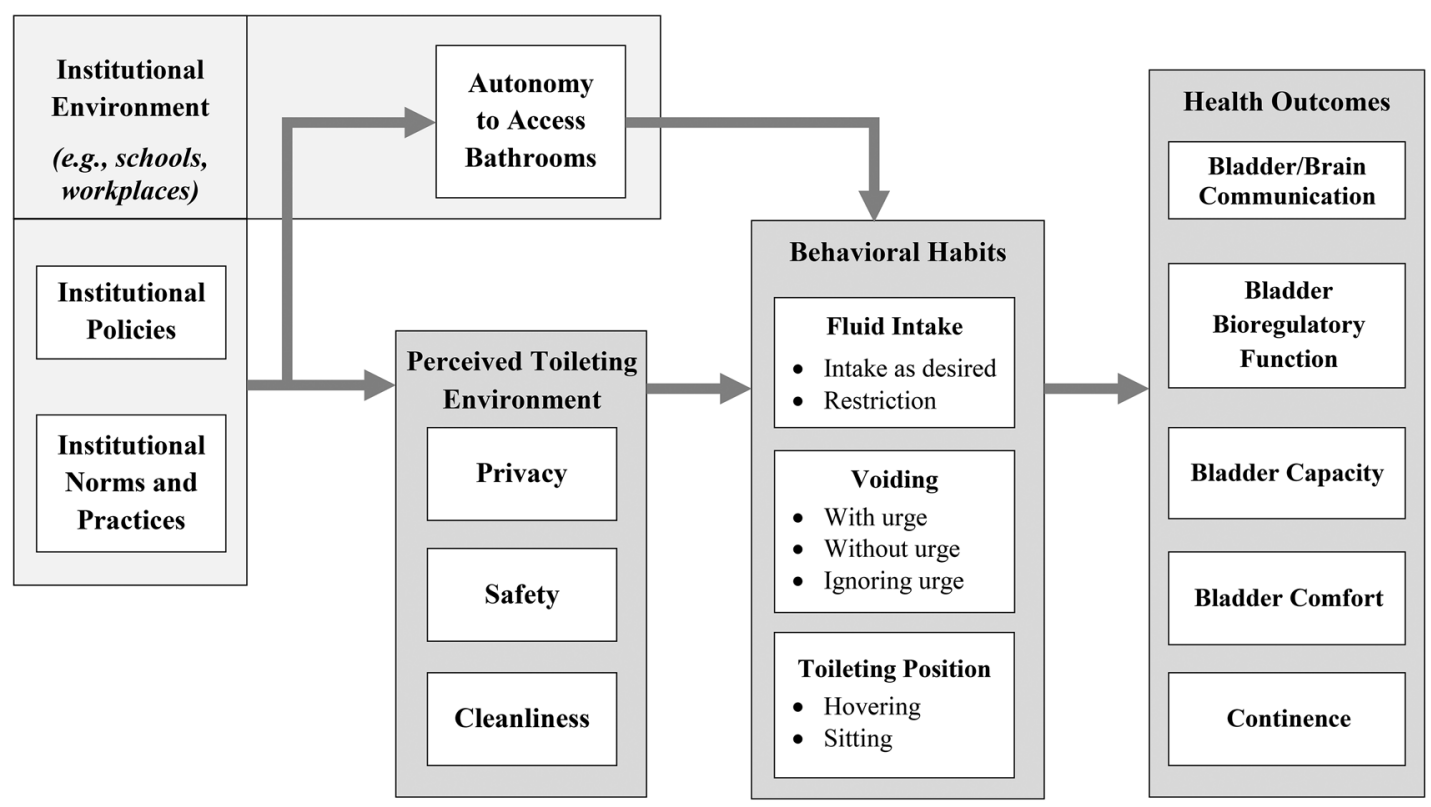

FIGURE 2 Sample conceptual model: Mechanisms by which schools and workplaces may influence bladder health and LUTS among girls and women (adapted from PLUS conceptual framework and Wang and Palmer) ${ }^{82}$ 

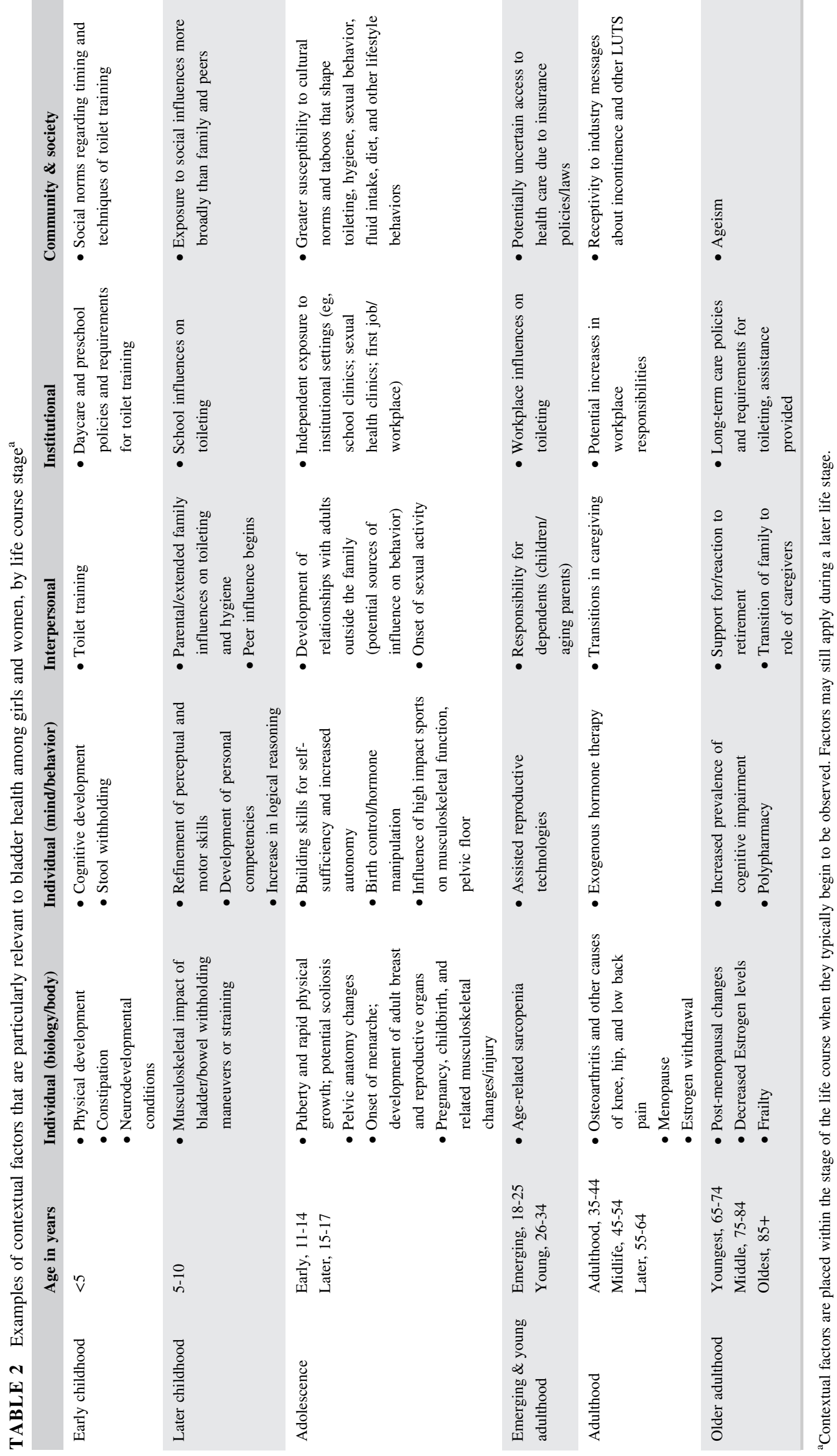
measuring, and statistically adjusting for potential confounders in analyses, a research team can better isolate the contribution of hypothesized risk and protective factors to LUTS and bladder health. Confidence in results is enhanced when multiple studies-with different samples, study designs, and analytic approaches-support the causal role of hypothesized risk and protective factors.

The PLUS research agenda is expected to be implemented in a manner that corresponds to phases of translational research. Fishbein et $\mathrm{al}^{77}$ recently refined and extended the phases of basic science translational research for application to prevention science. Current efforts of the Consortium correspond to the first phase, discovery science (T0), which involves the identification of risk and protective factors to inform future prevention efforts. Remaining phases of prevention science translational research ${ }^{77}$ correspond to future efforts of the PLUS Consortium, including methods and program development (T1), efficacy and effectiveness trials (T2), and real world applications and dissemination (T3). The time period necessary to demonstrate efficacy and effectiveness of prevention interventions will likely depend on a number of considerations, including the risk or protective factor being targeted (eg, school or workplace policy governing access to toilets, family- or peer-based toileting norms, individual toileting behaviors); the outcome being examined (eg, continence, UTI); the population of girls or women being studied (eg, those who are asymptomatic vs symptomatic, corresponding to primary vs secondary prevention); and the period of time during which the LUTS under study typically develop. While it is difficult to anticipate the specific amount of time necessary to demonstrate efficacy or effectiveness of a prevention intervention, allowing 6 months to a year would be a reasonable initial approach. Degree of bladder health and LUTS should be examined, as opposed to an outcome that does not facilitate the identification of promising trends. In addition, it is important to examine whether the prevention intervention successfully altered the targeted risk and protective factors.

It is anticipated that phases T0-T3 will be followed by scaling and policy reform (T4), which involves wide-scale implementation, adoption, and institutionalization of new guidelines, practices, and policies. ${ }^{77}$ The final phase of prevention science translational research is globalization and public opinion (T5), which involves the cultivation of a fundamental and universal change in social systems, including policies and norms that promote bladder health. ${ }^{77}$ Phases T4 and T5 will allow the PLUS Consortium to impact social determinants of health, and potentially, structural determinants of health inequities. ${ }^{52}$ In addition to policy changes within organizations, legislation may be enacted to ensure that all members of a diverse society are embedded within institutions and communities that promote health. This approach is consistent with calls to ensure "potty parity" with respect to the planning and design of public restrooms. ${ }^{78}$

While the PLUS conceptual framework and prevention science paradigm promotes rigorous science, additional approaches are needed to ensure that the Consortium's research is informed by the lived experiences of girls and women and that resulting prevention interventions are likely to be wellreceived. For this reason, the PLUS Consortium is examining the extent to which community engagement principles can be incorporated into initial and ongoing activities. Authentic engagement with community stakeholders allow scientists and practitioners to mobilize resources, influence systems, and serve as catalysts for changing programs, practices, and policies. $^{79-81}$

\section{CONCLUSIONS}

The PLUS Research Consortium was established by the National Institutes of Health in 2015 to expand research beyond the detection and treatment of LUTS to the promotion and preservation of bladder health and prevention of LUTS. The PLUS Consortium is tasked with significantly expanding the prevention science literature on LUTS and promotion of bladder health. PLUS Consortium work is premised on the notion that programs, practices, and policies designed to promote health will have optimal impact if the conceptual foundation upon which efforts are based is comprehensive and informed by multiple disciplines. The tables and figures of this manuscript are tools that can be used to select, prioritize, and model risk and protective factors for study by all scientists interested in bladder health. The PLUS conceptual framework provides a foundation for developing prevention interventions that have the greatest likelihood of promoting and preserving bladder health among diverse populations.

While the Consortium's work is focused on prevention of LUTS and promotion of bladder health, the PLUS conceptual framework is broadly applicable to any domain of health that has historically focused on the treatment of illness and symptoms rather than the promotion of health. It is also broadly applicable to domains of health that have been examined from a predominantly biological or social ecological perspective, without integration of both perspectives. Work of the PLUS Consortium will contribute to the rich, evolving history and practice of prevention science, as well as the conceptualization of public health.

\section{ACKNOWLEDGMENTS}

The Prevention of Lower Urinary Tract Symptoms (PLUS) Research Consortium is supported by the National Institutes of Health $(\mathrm{NIH})$ through cooperative agreements (grants U01DK106786, U01DK106853, U01DK106858, U01DK1 06898, U01DK106893, U01DK106827, U01DK106908, U01DK106892). Additional support is provided by the 
National Institute on Aging, NIH Office of Research on Women's Health, and NIH Office of Behavioral and Social Sciences Research. The content of this article is solely the responsibility of the authors and does not necessarily represent the official views of the NIH or the U.S. Department of Veterans Affairs.

Participating research centers at the time of this writing are as follows:

\section{Loyola University Chicago-Maywood, Illinois}

Linda Brubaker, MD, MS, Multi-PI; Elizabeth Mueller, MD, MSME, Multi-PI; Colleen M. Fitzgerald, MD, MS, Investigator; Cecilia T. Hardacker, RN, MSN, Investigator; Jeni Hebert-Beirne, $\mathrm{PhD}, \mathrm{MPH}$, Investigator; Missy Lavender, MBA, Investigator; David A. Shoham, $\mathrm{PhD}$, Investigator.

University of Alabama at Birmingham—Birmingham, Alabama

Kathryn Burgio, PhD, PI; Cora Beth Lewis, MD, Investigator; Alayne Markland, DO, MSc, Investigator; Gerald McGwin, $\mathrm{PhD}$, Investigator; Beverly Williams, $\mathrm{PhD}$, Investigator.

University of California San Diego-La Jolla, California

Emily S. Lukacz, MD, PI; Sheila Gahagan, MD, MPH, Investigator; D. Yvette LaCoursiere, MD, MPH, Investigator; Jesse N. Nodora, DrPH, Investigator.

University of Michigan-Ann Arbor, Michigan

Janis M. Miller, PhD, MSN, PI; Lawrence Chin-I An, $\mathrm{MD}$, Investigator; Lisa Kane Low, PhD, MS, CNM, Investigator.

University of Pennsylvania-Urology, Philadelphia, Pennsylvania

Diane Kaschak Newman, DNP, ANP-BC, FAAN PI; Amanda Berry, PhD, CRNP, Investigator; C. Neill Epperson, MD, Investigator; Kathryn H. Schmitz, PhD, MPH, FACSM, FTOS, Investigator; Ariana L. Smith, MD, Investigator; Ann Stapleton, MD, FIDSA, FACP, Investigator; Jean Wyman, $\mathrm{PhD}, \mathrm{RN}, \mathrm{FAAN}$, Investigator.

Washington University in St. Louis-St. Louis, Missouri

Siobhan Sutcliffe, PhD, PI; Colleen McNicholas, DO, MSc, Investigator; Aimee James, $\mathrm{PhD}$, MPH, Investigator; Jerry Lowder, MD, MSc, Investigator; Mary Townsend, ScD, Investigator.

Yale University-New Haven, Connecticut

Leslie Rickey, MD, PI; Deepa Camenga, MD, MHS, Investigator; Toby Chai, MD, Investigator; Jessica B. Lewis, LMFT, MPhil, Investigator.

NIH Program Office: National Institute of Diabetes and Digestive and Kidney Diseases, Division of Kidney, Urologic, and Hematologic Diseases, Bethesda, Maryland

NIH Project Scientist: Tamara Bavendam MD, MS; Project Officer: Ziya Kirkali, MD; Scientific Advisors: Chris
Mullins, PhD and Jenna Norton, MPH; Steering Committee Chair: Mary H. Palmer, PhD.

Scientific and Data Coordinating Center (SDCC): University of Minnesota-Minneapolis, Minnesota

Bernard Harlow, PhD, Multi-PI; Kyle Rudser, PhD, Multi-PI; Sonya S. Brady, PhD, Investigator; John Connett, $\mathrm{PhD}$, Investigator; Haitao $\mathrm{Chu}, \mathrm{MD}, \mathrm{PhD}$, Investigator; Cynthia Fok, MD, MPH, Investigator; Sarah Lindberg, MPH, Investigator; Todd Rockwood, PhD, Investigator; The PLUS Research Consortium also acknowledges the contributions of retired Steering Committee Chair, Denise Simons-Morton, MD, MPH, PhD.

\section{CONFLICTS OF INTEREST}

The authors have no conflicts of interest to declare.

\section{ORCID}

Sonya S. Brady (iD http://orcid.org/0000-0001-8660-9308

\section{REFERENCES}

1. Schneider M. Public health: sciences, politics, and prevention. Introduction to Public Health. 5th ed. Burlington: Jones \& Bartlett Learning; 2017.

2. Abrams P, Andersson KE, Birder L, et al. Fourth international consultation on incontinence recommendations of the international scientific committee: evaluation and treatment of urinary incontinence, pelvic organ prolapse, and fecal incontinence. Neurourol Urodyn. 2010;29:213-240.

3. Haylen BT, De Ridder D, Freeman RM, et al. An International Urogynecological Association/International Continence Society joint report on the terminology for female pelvic floor dysfunction. Neurourol Urodyn. 2010;29:4-20.

4. Minassian VA, Bazi T, Stewart WF. Clinical epidemiological insights into urinary incontinence. Int Urogynecol J. 2017;28: 687-696.

5. Norton P, Brubaker L. Urinary incontinence in women. Lancet. 2006;367:57-67.

6. Milsom I, Abrams P, Cardozo L, et al. How widespread are the symptoms of an overactive bladder and how are they managed? A population-based prevalence study. BJU Int. 2001;87:760-766.

7. Stewart WF, Van Rooyen JB, Cundiff GW, et al. Prevalence and burden of overactive bladder in the United States. World J Urol. 2003;20:327-336.

8. Overactive Bladder Medications. http://www.drugs.com/condition/ urinary-frequency.html. Accessed September 27, 2014.

9. Rovner ES, Wein AJ. Treatment options for stress urinary incontinence. Rev Urol. 2004;6:S29-S47.

10. Coyne KS, Wein A, Nicholson S, et al. Economic burden of urgency urinary incontinence in the United States: a systematic review. J Manag Care Pharm. 2014;20:130-140.

11. Griebling TL. Urologic diseases in America project: trends in resource use for urinary tract infections in men. J Urol. 2005; 173:1288-1294. 
12. Griebling T. Urologic diseases in America project: trends in resource use for urinary tract infections in women. $J$ Urol. 2005;173:1281-1287.

13. Markland AD, Richter HE, Fwu CW, et al. Prevalence and trends of urinary incontinence in adults in the United States, 2001 to 2008. J Urol. 2011;186:589-593.

14. Tennstedt SL, Link CL, Steers WD, et al. Prevalence of and risk factors for urine leakage in a racially and ethnically diverse population of adults: the Boston Area Community Health (BACH) survey. Am J Epidemiol. 2008;167:390-399.

15. Sexton CC, Coyne KS, Kopp ZS, et al. The overlap of storage, voiding and postmicturition symptoms and implications for treatment seeking in the USA, UK and Sweden: EpiLUTS. BJU Int. 103:12-23.

16. Aoki $\mathrm{Y}$, Brown $\mathrm{H}$, Brubaker L, et al. Urinary incontinence in women. Nat Rev Dis Prim. 2017;3:17042.

17. Greed C. Global gendered toilet provision. In: More Public than Private: Toilet Adoption and Menstural Hygiene Management II in AAG Annual Conference. Tampa; 2014.

18. Coyne KS, Sexton CC, Thompson CL, et al. The prevalence of lower urinary tract symptoms (LUTS) in the USA, the UK and Sweden: results from the epidemiology of LUTS (EpiLUTS) study. BJU Int. 2009;104:352-360.

19. Wu JM, Matthews CA, Vaughan CP, et al. Urinary, fecal, and dual incontinence in older U.S. adults. J Am Geriatr Soc. 2015;63:947-953.

20. Butler RJ, Heron J. The prevalence of infrequent bedwetting and nocturnal enuresis in childhood. Scand J Urol Nephrol. 2008;42: 257-264.

21. Mazzola BL, von Vigier RO, Marchand S, et al. Behavioral and functional abnormalities linked with recurrent urinary tract infections in girls. J Nephrol. 2003;16:133-138.

22. Raz R, Gennesin Y, Wasser J, et al. Recurrent urinary tract infections in postmenopausal women. Clin Infect Dis. 2000;30: 152-156.

23. Coyne KS, Kaplan SA, Chapple CR, et al. Risk factors and comorbid conditions associated with lower urinary tract symptoms: EpiLUTS. BJU Int. 2009;103:24-32.

24. Coyne KS, Wein AJ, Tubaro A, et al. The burden of lower urinary tract symptoms: evaluating the effect of LUTS on health-related quality of life, anxiety and depression: EpiLUTS. BJU Int. 2009;103:4-11.

25. Grimby A, Milsom I, Molander U, et al. The influence of urinary incontinence on the quality of life of elderly women. Age Ageing. 1993;22:82-89.

26. Minassian VA, Yan X, Lichtenfeld MJ, et al. The iceberg of health care utilization in women with urinary incontinence. Int Urogynecol J. 2012;23:1087-1093.

27. Elstad EA, Taubenberger SP, Botelho EM, et al. Beyond incontinence: the stigma of other urinary symptoms. $J$ Adv Nurs. 2010;66:2460-2470.

28. Mandimika CL, Murk W, Muhlhauser McPencow A, et al. Knowledge of pelvic floor disorders in a population of community-dwelling women. Am J Obstet Gynecol. 2014;210: e161-e169.

29. Welch LC, Taubenberger S, Tennstedt SL. Patients' experiences of seeking health care for lower urinary tract symptoms. Res Nurs Health. 2011;34:496-507.

30. Dick-Rath D. DDR on DTC: Myrbetniq. 2014. MM\&M: Channel, Pharmaceutical. http://www.mmm-online.com/pharmaceutical/ddron-dtc-myrbetriq/article/343550/.
31. Wong E. Adult incontinence category is booming. 2010. Adweek: brand marketing. http://www.adweek.com/brand-marketing/adultincontinence-category-booming-107139/.

32. Lee Ventola C. Direct-to-consumer pharmaceutical advertising: therapeutic or toxic? Pharm Ther. 2011;36:669-684.

33. Freudenberg N. Lethal But Legal: Corporations, Consumption, and Protecting Public Health. USA: Oxford University Press; 2014.

34. Institute of Medicine (US) Committee on Assuring the Health of the Public in the 21st Century. The Future of the Public's Health in the 21st Century. Washington, DC: National Academies Press (US); 2002.

35. Cradock AL, Barrett JL, Kenney EL, et al. Using cost-effectiveness analysis to prioritize policy and programmatic approaches to physical activity promotion and obesity prevention in childhood. Prev Med (Baltim). 2017;95:S17-S27.

36. Lin JS, O'Connor E, Whitlock EP, Beil TL. Behavioral counseling to promote physical activity and a healthful diet to prevent cardiovascular disease in adults: a systematic review for the U.S. Preventive Services Task Force. Ann Intern Med. 2010;153: 736-750.

37. Barzi A, Lenz HJ, Quinn DI, et al. Comparative effectiveness of screening strategies for colorectal cancer. Cancer. 2017;123: $1516-1527$.

38. Rémy V, Largeron N, Quilici S, et al. The economic value of vaccination: why prevention is wealth. J Mark Access Heal Policy ISSN J. 2017;3:29284.

39. Boyle R, Hay-Smith EJC, Cody JD, et al. Pelvic floor muscle training for prevention and treatment of urinary and fecal incontinence in antenatal and postnatal women: a short version cochrane review. Neurourol Urodyn. 2014;33:269-276.

40. Diokno AC, Sampselle CM, Herzog AR, et al. Prevention of urinary incontinence by behavioral modification program: a randomized, controlled trial among older women in the community. $J$ Urol. 2004; 17:1165-1171.

41. Perrotta C, Aznar M, Mejia R, et al. Oestrogens for preventing recurrent urinary tract infection in postmenopausal women. Cochrane Database Syst Rev. 2008;CD005131. https://doi.org/ 10.1002/14651858.CD005131.pub2

42. Sampselle CM, Newman DK, Miller JM, et al. A randomized controlled trial to compare 2 scalable interventions for lower urinary tract symptom prevention: main outcomes of the TULIP study. J Urol. 2017;197:1480-1486.

43. Harlow BL, Bavendam TG, Palmer MH, et al. The Prevention of Lower Urinary Tract Symptoms (PLUS) Research Consortium: a transdisciplinary approach toward promoting bladder health and preventing lower urinary tract symptoms in women across the life course. J Womens Health. 2018;27:283-289.

44. Lukacz ES, Bavendam TG, Berry A, et al. A novel research definition of bladder health in women and girls: Implications for research and public health promotion. J Womens Health. 2018; PMID: 29792542, [Epub ahead of print]. https://doi.org/10.1089/ jwh.2017.6786

45. World Health Organization. Constitution of the world health organization. Basic Doc Forthy. 5th ed. Geneva, Switzerland: WHO Press; 2006.

46. Coie JD, Watt NF, West SG, et al. The science of prevention: a conceptual framework and some directions for a national research program. Am Psychol. 1993;48:1013-1022. 
47. Heller K. Coming of age of prevention science. Comments on the 1994 national institute for mental health-institute of medicine prevention reports. Am Psychol. 1996;51:1123-1127.

48. Viner RM, Ozer EM, Denny S, et al. Adolescence and the social determinants of health. Lancet. 2012;379:1641-1652.

49. World Health Organization and Calouste Gulbekian Foundation. Social Determinants of Mental Health. Geneva, Switzerland: WHO Press; 2014.

50. Society for Prevention Research. (2011). Standards of knowledge for the science of prevention. Retrieved from: http://www.preven tionresearch.org/conferences/publications/standards-of-knowledge

51. Glass TA, McAtee MJ. Behavioral science at the crossroads in public health: extending horizons, envisioning the future. Soc Sci Med. 2006;62:1650-1671.

52. Solar O, Irwin A. 2010. A conceptual framework for action on the social determinants of health. Social Determinants of Health Discussion Paper 2 (Policy and Practice). Geneva, Switzerland: World Health Organization (WHO) Document Production Services.

53. Sallis J, Owen N. Ecological models of health behavior. In: Glanz K, Rimer B, Viswanath K, eds. Health Behavior: Theory, Research, and Practice. 5th ed. San Francisco: Jossey Bass; 2015.

54. Brofenbrenner U. Toward an experimental ecology of human development. Am Psychol. 1977;32:513-531.

55. Richard L, Gauvin L, Raine K. Ecological models revisited: their uses and evolution in health promotion over two decades. Annu Rev Public Health. 2011;32:307-326.

56. Braveman P, Egerter S, Williams DR. The social determinants of health: coming of age. Annu Rev Public Health. 2011;32:381-398.

57. Eichelberger K, Doll K, Ekpo G, et al. Black Lives Matter: claiming a space for evidence-based outrage in obstetrics and gynecology. Am J Public Health. 2016;106:1771-1772.

58. Frieden TR. A framework for public health action: the health impact pyramid. Am J Public Health. 2010;100:590-595.

59. Golden SD, Earp JA. Social ecological approaches to individuals and their contexts: twenty years of health education \& behavior health promotion interventions. Heal Educ Behav. 2012;39:364-372.

60. Bauman AE, Reis RS, Sallis JF, et al. Correlates of physical activity: why are some people physically active and others not? Lancet. 2012;380:258-271.

61. Institute of Medicine. Health and Behavior: The Interplay of Biological, Behavioral, and Societal Influences. Washington, DC: National Academies Press (US); 2001.

62. World Health Organization. Global action plan for the prevention and control of noncommunicable diseases 2013-2020. World Health Organization. 2013. http://www.who.int/iris/handle/10665/ 94384

63. Engel GL. The need for a new medical model: a challenge for biomedicine. Science (80). 1977;196:129-136.

64. Engel GL. The clinical application of the Biopsychosocial model. J Med Philos. 1981;6:101-123.

65. Suls J, Green PA, Davidson KW. A biobehavioral [corrected] framework to address the emerging challenge of multimorbidity. Psychosom Med. 2016;78:281-289.

66. Rosenbaum DL, White KS. Understanding the complexity of biopsychosocial factors in the public health epidemic of overweight and obesity. Heal Psychol Open. 2016;3:2055102916634364.

67. Henningsen P. Still modern? Developing the biopsychosocial model for the 21st century. J Psychosom Res. 2015;79:362-363.
68. Krieger N. Embodiment: a conceptual glossary for epidemiology. $J$ Epidemiol Community Health. 2005;59:350-355.

69. Healthy People 2020: Disparities. Washington DC: U.S. Department of Health and Human Services, Office of Disease Prevention and Health Promotion. https://www.healthypeople.gov/2020/about/ foundation-health-measures/Disparities\#top. Accessed April 27, 2018.

70. Braveman P. What are health disparities and health eduity? We need to be clear. Public Health Rep. 2014;129:5-8.

71. Whitehead M. The concepts and principles of equity and health. Int J Heal Serv. 1992;22:429-445.

72. Earp J, Ennett S. Conceptual models for health education research and practice. Health Educ Res. 1991;6:163-171.

73. Hagan JJ, Shaw J, Duncan P, eds, Bright Futures: Guidelines for Health Supervision of Infants, Children and Adolescents. 4th ed. Itasca, IL: American Academy of Pediatrics; 2017. https://www. aap.org/en-us/Pages/Contact.aspx

74. Arnett JJ. Emerging adulthood: a theory of development from the late teens through the twenties. Am Psychol. 2000;55:469-480.

75. Segen J. Concise Dictionary of Modern Medicine. New York: McGraw-Hill; 2006.

76. Greenland S, Robins JM, Pearl J. Confounding and collapsibility in causal inference. Stat Sci. 1999;14:29-46.

77. Fishbein DH, Ridenour TA, Stahl M, et al. The full translational spectrum of prevention science: facilitating the transfer of knowledge to practices and policies that prevent behavioral health problems. Transl Behav Med. 2016;6:5-16.

78. Anthony KH, Dufresne M. Potty parity in perspective: gender and family issues in planning and designing public restrooms. J Plan Lit. 2007;21:267-294.

79. Ahmed SM, Palermo AGS. Community engagement in research: frameworks for education and peer review. Am J Public Health. 2010;100:1380-1387.

80. Cacari-Stone L, Wallerstein N, Garcia AP, et al. The promise of community-based participatory research for health equity: a conceptual model for bridging evidence with policy. Am J Public Health. 2014;104:1615-1623.

81. Woolf SH, Zimmerman E, Haley A, et al. Authentic engagement of patients and communities can transform research, practice, and policy. Health Aff. 2016;35:590-594.

82. Wang K, Palmer MH. Women's toileting behaviour related to urinary elimination: concept analysis. J Adv Nurs. 2010;66:1874-1884.

\section{SUPPORTING INFORMATION}

Additional supporting information may be found online in the Supporting Information section at the end of the article.

How to cite this article: Brady SS, Bavendam TG, Berry A, et al. The Prevention of Lower Urinary Tract Symptoms (PLUS) in girls and women: Developing a conceptual framework for a prevention research agenda. Neurourology and Urodynamics. 2018;37: 2951-2964. https://doi.org/10.1002/nau.23787 